\title{
ODEL OF DYNAMIC INTEGRATION OF LEAN SHOP FLOOR MANAGEMENT WITHIN THE ORGANIZATIONAL MANAGEMENT SYSTEM
}

\author{
VIRGINIA IUGA \\ Faculty of Engineering/ Department of Engineering and Management, "Lucian Blaga" University, Sibiu, \\ Romania, virginiaiuga@gmail.com \\ CLAUDIU KIFOR \\ Faculty of Engineering/ Department of Engineering and Management, "Lucian Blaga" University, Sibiu, \\ Romania, claudiu.kifor@ulbsibiu.ro
}

\begin{abstract}
The key to achieve a sustainable development lies in the customer satisfaction through improved quality, reduced cost, reduced delivery lead times and proper communication. The objective of the lean manufacturing system (LMS) is to identify and eliminate the processes and resources which do not add value to a product. The following paper aims to present a proposal of further development of integrated management systems in organizations through the implementation of lean shop floor management. In the first part of the paper, a dynamic model of the implementation steps will be presented. Furthermore, the paper underlines the importance of implementing a lean culture parallel with each step of integrating the lean methods and tools. The paper also describes the Toyota philosophy, tools, and the supporting lean culture necessary to implementing an efficient lean system in productive organizations.
\end{abstract}

tools

Key words: lean manufacturing, model, management systems, shop floor management, hard \& soft lean

\section{Introduction}

The speed at which the industry, especially the automotive industry, is more and more present in the economical environment leads to the indispensability of "Lean" concepts. This not only remains a Japanese theory, but is developed into concrete models in order to integrate them into actual production systems.

In today's global competitive business scenario, customer satisfaction at competitive prices, quality and the on time delivery will provide the basis for successful development of organizations. LMS provide a competitive strategy to achieve this necessary sustainable development. It is already internationally recognized that the implementation of lean concepts is an indispensable part of organizational strategies for making processes more efficient within companies. Nowadays the target of an organization is to reach the stage at which the organization's management systems are integrated so that they can respect all the needs of the interested parties: clients, shareholders, employees, local administration, civil society, legal requirements.

The objective of this paper lies in underlining the essential implementation steps of a lean manufacturing system in existing management systems.

The first chapter describes, from an economic point of view, the necessity to implement lean manufacturing systems within the organizational system. Chapter 3 introduces a new dynamic model, the "Time to become lean" model. After a brief overview of the concept and the key pillars of the model, this paper will analyze and explain the key steps that need to be taken in order to successfully implement the model within the organization so that valuable conclusions and future research directions can be derived. 


\section{Economic aspects}

The first requirement of any organization, the essential one, the one of survival which ensures the existence of every organization is creating profit. The extremely simple equation of profit seen as the difference between financial income and expenses is:

$$
\text { Profit = incomes }- \text { expenses (1) }
$$

Following the rational economical thinking, it is necessary that the result of this difference is positive in order to assure an ongoing existence of an organization. Respectfully, to ensure the durability and stability of the organization, this positive result must be either maintained on the long term under the circumstances of a fluctuant market or economic crisis or with organizational resources that have to exist in order to compensate for a negative outcome in the following period.

This implies a high degree of flexibility within an organization.

In order to achieve this goal an organization usually acts on the both terms of the equation (1):

- increasing incomes and

- reducing expenses

Increasing incomes automatically implies ensuring constant sales or optimally ensuring customer fidelity resulting in a constant increase in the number of customers.

The main instrument for this purpose is the optimal relationship of the quality price report of products and/or services. The term "quality" used in this context is of neither integrated quality which incorporates nor only the literal meaning of quality but also safety criteria, civil responsibility for the produce/service, social impact and risk management.

Each of these criteria represents a management system. All together these management systems blend into the organization. In the proposed model these management systems are represented as a shell, ensuring stability within the organization.

Reducing expenses represents the second term of the equation. Organizations have started even from the 80s to analyze how expenses can be reduced bearing in mind the requirements of the interested parts regarding product quality, organizational impact on the environment, the requirements regarding ensuring a safe and secure organizational and work safety and so on. The solution is represented by eliminating waste from the organization.

Scientific researcher Rose (2010) has shown that the potential to reduce waste is enormous, the added value and non-added value are for most industrial operations as follows:

- $5 \%$ of activities add value

- $\quad 35 \%$ are necessary non value added activities

- $\quad 60 \%$ add no value at all

The main goal of the LM system is therefore to eliminate the waste in all areas of the business, and more specifically to eliminate activities that the customer does not want to pay for.

"Time to become lean" - dynamic implementation model of lean shop floor management

The "Time to become lean" model proposes the engraftment within the stages of lean management and the management systems of the organization. While the management system ensures the existence of the organization through satisfying quality needs, producing security and stability of the manufacturing process, the "lean" concept comes in form of an addendum to ensure the optimal quality price ratio through eliminating waste.

\subsection{Concept}

For this paper we used two original concepts: the concept of the hard and soft tools.

\subsubsection{Hard tools}

According to Liker and Meier (2006), hard tools are defined to be all the classical lean methods and tools, which are worldwide standardised.

The most usual methods and tools which are mandatory to be implemented in a lean shop floor are:

- 5S - is the workplace organization through the steps "Sort", "Straighten", "Shine", "Standardize" and "Sustaine".

- Andon - control device that indicates the status of a machine.

- Chaku-Chaku - equipment that ejects the finished piece for the operator so that the operator can go from machine to machine within a cell.

- Heijunka - leveling the load of the station or production line.

- Jidoka - stopping a line automatically when a quality error is detected.

- Kanban - production control process through cards, signs, containers, boxes and so on, which triggers movement in the downstream process flow of products between workstations. 
- One-Piece Flow (Single-Piece Flow)-production type that implies processing and moving pieces from one workplace to the other, piece by piece.

- Poka Yoke - method/device for preventing errors.

- Pull Production - production and delivery system in which an upstream workstation does not produce any item as long as the downstream workstation does not signal that it needs something.

- Single-Minute Exchange of Die (SMED) - equipment changes from one physical state to another.

\subsubsection{Soft tools}

Soft tools are LM's aspects related to the human resources like: lean culture, lean thinking seen parallel and complementary to the "hard tools".

These soft tools are unique in each organization and can not be, in our opinion, reproduced through copy \& paste. Nevertheless, they have to be built parallel at each hard step implementation.

According to Upadhye et al. (2010) Just in Time (JIT) systems requires a work culture that allows the worker to become a participant in the process of decision making. More than that, if necessary it allows putting trust and responsibility in the hands of the workers.

\subsection{The pillars}

The two triangles at the base represent the pillars of the model. The pillars ensure the correct and durable functioning of the integrated management system. The pillars referring to management respective to employees are "Management Commitment" and "Knowledge Management”.

- Management Commitment: the general agreement and the synchronized action of the entire managerial staff in maintaining integrated management systems.

- Knowledge Management: representing the essence, the essential value of the organization as added value creators. Their abilities and coordinated action in the organization is achieved through knowledge management.

Figure 1: Time to become lean: Proposed lean shop floor implementation model

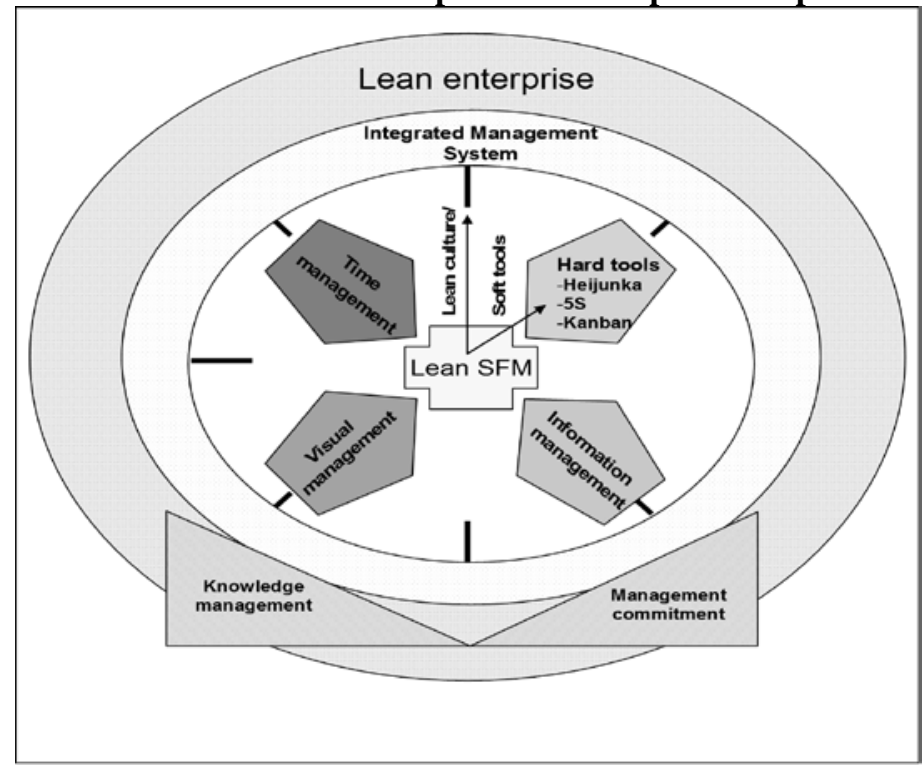

In other words, these fundaments are assured through the human factor of an organization. On the one hand, the fundament is comprised of management through its commitment. On the other hand, it is through the employees and their developed abilities.

The two fundamental stepping stones responsible for the durable stability of the organization. 


\subsection{The implementation of the "Time to become lean" model}

The implementation of the model can be broken down into four easy steps: hard tools implementation, informational management, visual management and time management.

\subsubsection{Hard tools implementation}

Hard tools implementation is the step of implementing the standard lean Instruments within the organization.

The "Soft tools" will act in this stage through the flexible choice of the most appropriate instruments for the organization and the adaption of these tools depending on organizational needs, through avoidance of templates. Practice has demonstrated that implementing some instruments through copying even from Toyota, no matter how spectacularly efficient they have proved to be in other organizations, represents a very short termed victory. The organizational culture has the role to annihilate the natural resistance of the organization in front of change through changing from the inside to the outside, towards adapting mentalities and increasing the level of change acceptability. These instruments must match exactly the needs of the organization, and must be adapted to the production type.

\subsubsection{Informational Management}

The "Informational Management" step implies redesigning the informational management from four angles.

$\checkmark$ Redefining the performance indicators (KPI's) after the following criteria: utility for the proposed objective (managing processes), accessibility, facilitating their handling, the width of the collecting and reporting/auxiliary activities needs, the complexity of the hard equipment necessary for data collection, the cost of necessary handling programs (software), the necessary qualification of the employees.

The purpose is to choose the right KPI's so that they are simple and easy to handle.

The clock pins (soft tools) will designate in this phase the focus on defining the indicators utilized in shop floor so that they will be understood and accepted by the personnel that works on this level and with briefing and involving data personnel.

$\checkmark$ Projecting the utilization steps of the indicators/ groups of indicators corresponding to the hierarchic layers of the personnel organization.

The lean organizational culture will be in this stage responsible for defining the indicator groups so that the two types of waste most frequently stumbled upon the informational level (over-information and under-information) will be avoided.

\section{$\checkmark$ Establishing handling environment}

In this stage the action plan is to apply the principle of simplicity to eliminate waste and implement the green \& lean philosophy (Bergmiller and McWright, 2009).

Concretely in this phase the following are surveyed:

- Attaining the information from the shop floor personnel as soon as possible,

- Reducing the usage of informational supports and complicated software,

- Reducing the bureaucracy and the usage of paper supports for stocking information, choosing environment that will allow real time actualization.

The concept of waste elimination that will be focused in this phase is the one of returning to "naturalness", avoiding costly investments in software and programs, in complicated trainings to manage some indicators.

$\checkmark$ Establishing the frequency of actualization

In this stage the prudency in planning the actualization frequency of KPI's will be monitored. In the focus there must also be the fact that this action implies resource consumption. The main criterion for actualization is the moment in which the added value given by the information can be capitalized.

Organizations often forget to ask themselves questions like: "What is the use of this indicator?", "Is it useful for managing the processes?", "Is it useful to recognize the deviations in real time?" "Is it useful in surveying the deviation removing measures?".

Within this stage, the "Soft tools" are responsible for utilizing friendly environment for shop floor by using the direct data registration technique in the Gemba like the white board, the pin board and other simple instruments like: markers, colored notes, cardboards and so on.

\subsubsection{Visual management}


Visual management focuses on redesigning the lean bases visualization in shop floor. The visualization concept must be focused on the criteria of "five minutes management instead of fifty minutes presentation”. According to Maasaki (2004), a performing visual management means "the ability to understand a production zone in five minutes or less, through a simple observation, without using a computer and without talking with somebody". The aim is to design a transparent visual management system, so that the administration can recognize the need to act in a timely manner.

The clock pins will function in a manner that reduces the waste created by the decision waiting time. This decision waiting time can either, in the most favorable scenario, lead to the stop of the production process or, in the most unfavorable scenario, to a continuous production. A continuous production can though result in ultimately having to be repair or destroy produced pieces.

\subsubsection{Time management}

Time management consists of planning time at all hierarchical levels, standardizing this planning and focusing on the time spent in the Gemba.

Currently in most organizations, the top management reviews reports containing indicators and uses those indicators for decision-making purposes. The problem consists precisely in the fact that often these decisions are based only on those indicators, which are often in excess or text information and are not anchored in the production reality.

In most organizations, like the automotive industry which is considered to be the most dynamic one, the working schedule of a team leader can look like in the following graph:

Figure 2: Daily schedule of a team leader

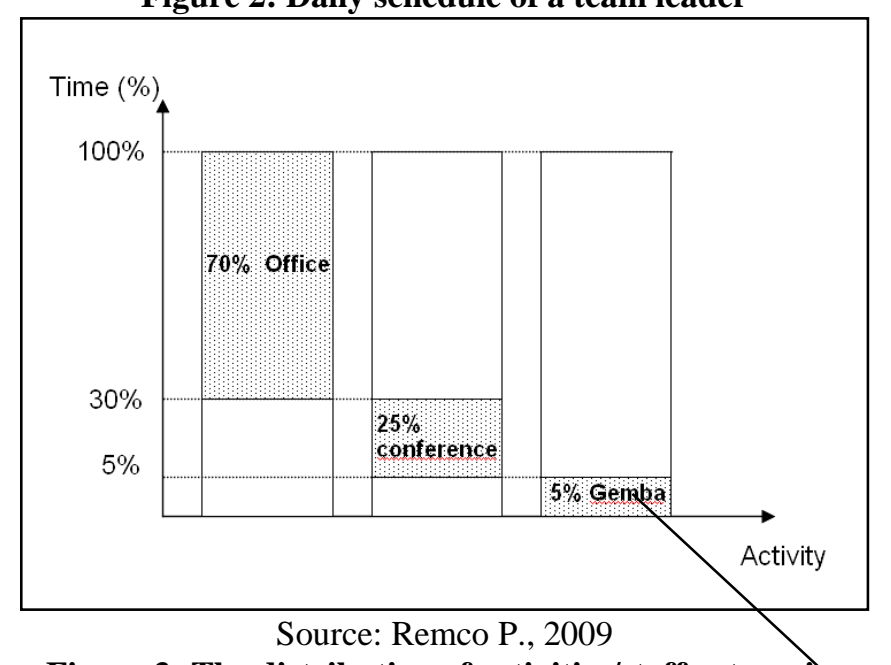

Figure 3: The distribution of activities/staff categories

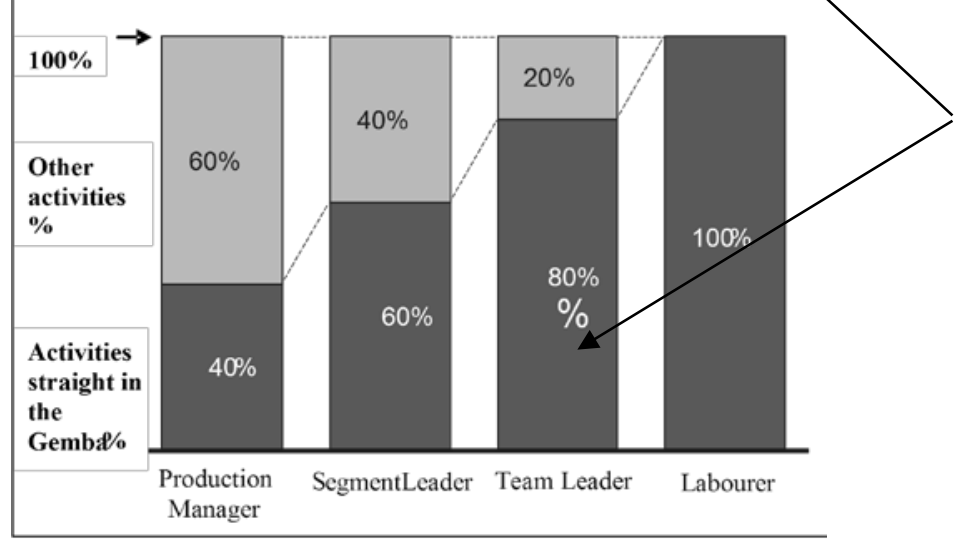

Source : Koller T. et al., 2010

The standardization will be based on obtaining a time scheduling situation like in figure 3.

Taking into consideration the comparison with the actual situation of time allocation, the improvement is visible (from $5 \%$ to $80 \%$ time in Gemba). The soft tools will operate here on implementing the "Go \& See" (Genchi Genbutsu) standard on replacing the "meeting and/or mail". The presence of efficient and very fast problem focused management leads to a direct relationship, oriented towards optimizing processes on behalf of the direct productive staff with spectacular effects in increasing the efficiency of decision making. The manager should be perceived as the essential support 
factor in modifications, deviations from the normal processes and as the main trainer of their correct approach. The presence of Gemba, replacing discussions in conference rooms or offices, would result in a faster reaction to nonconformities, thus leading to the reduction of losses.

\subsection{Shop floor management}

The center and "heart" of the model is the shop floor management concept (SFM). This is the durable and viable "lean" organization core. SFM is in this context the set of bottom-up management standards starting from the production level all the way up to the top management level. The immediate effect is minimizing human resources consumption, followed by increasing the efficiency of the added value creating processes and personnel motivation achieved through creating a transparent management. Moreover, the effect extends to creating responsibly and involving the personnel in the effective leadership of the organization.

The time allocated for data collection, interpreting and decision making is greatly reduced. The model suggests that this core is reached in time frames following the Kaizen improvement principles with small steps and maintaining equilibrium. The order of the four key points that are to be achieved is that of the clock pins. They are approached sequentially and adapted to each existing culture of the organization.

\subsection{Lean enterprise}

When a stabilized level of lean production, organizational culture and management integrated system way of organizing is reached, the organization will position itself as a lean enterprise. This implies extending the core from SFM towards customers and suppliers. This concept derives from the Toyota philosophy and refers to aligning the relationships with entities outside the company: suppliers and customers.

According to Liker et al. (2006), the steps that ensure this are:

- $\quad$ Being a role model lean customer for the suppliers

- $\quad$ Identifying the core competencies

- $\quad$ Developing the core suppliers

- $\quad$ Implementing control systems for continuous improvement.

- $\quad$ Favoring an incremental approach

- $\quad$ Developing a mechanism for joint enterprise learning

The highest level of the lean enterprise takes place when the partners in the enterprise (customer supplier) are learning together and capturing the learning in a standardized processes. This way a sustainable development is ensured throughout the entire organizational chain.

\section{Conclusions}

The proposed model wants to show that Cumbo's (2006) statement "LM represents a set of tools and a stepwise strategy for achieving smooth, predictable product flow, maximum product flexibility, and minimum system waste" is only partially applicable because this minimizes the role of organizational culture. With the model "Time to become lean" we want to underline that LM is much more than a set of tools which can be implemented equally in Japan, America, Germany or Romania. Nevertheless, this cannot function in reality without organisational culture (soft tools), which involves a considerable amount of knowledge and risks to the process.

The model was developed by taking into consideration Groen's (2012) conclusions that "to create and maintain a lean management system the main barrier is shop floor employee attitude". Initially, Ohno's theory lacked this approach. It is demonstrated that the functionality of the lean management in organisation can be achieved in two ways: one by continuous pressing done by the management which solution involves financial costs or the second, by creating the self-sustaining lean culture which means with depending on minimal financial efforts. The model was build to "cover" this second option.

Further research can be directed towards finding the variables implicated and to calculating the final savings resulted in an organization through using this model in the shop floor manufacturing.

\section{References}

- Bergmiller G.G.; McWright P.R. (2009) Parallel Models for Lean and Green Operations, Proceedings of the 2009 Industrial Engineering Research Conference, May 30 - June 3, Miami, FL.

- Cumbo, D.; Kline, D.E.; Bumgardner, M.S. (2006) Benchmarking performance measurement and lean manufacturing in the rough mil, Forest Products Journal, 56 (6), p. 25-30. 
- Groen, B.; Wouters M., Wilderom C. (2012) Why do employees take more initiatives to improve their performance after co-developing performance measures? A field study, Elsevier, Management Accounting Research, p. 120-141.

- Koller, T.; Gödhart, M.; Wessels D. (2010) Valuation: Measuring and Managing the Value of Companies, McKinsey \& Company Inc..

- $\quad$ Liker, J.; Meier, D. (2006) The Toyota Way Fieldbook, New York, McGraw Hill.

- Masaaki, I. (2004) Gemba Kaizen, Finmedia.

- Remco, P (2009) Führen am Ort der Wertschöpfung, Stuttgart: LogX Verlag.

- Rose, A.M.N.; Deros, B. Md.; Rahman M. N. Ab. (2010) Development of framework for lean manufacturing implementation in SMEs, The 11th Asia Pacific Industrial Engineering and Management Systems Conference, Melaka.

- Upadhye, N.; Deshmukh, S. G.; Garg, S. (2010) Lean manufacturing for sustainable development. Global Business and Management Research; 2 (1), p. 125-137. 